INEEL/EXT-02-00084

\title{
Field Operations Program U.S. Postal Service - Fountain Valley Electric Carrier Route Vehicle Testing
}

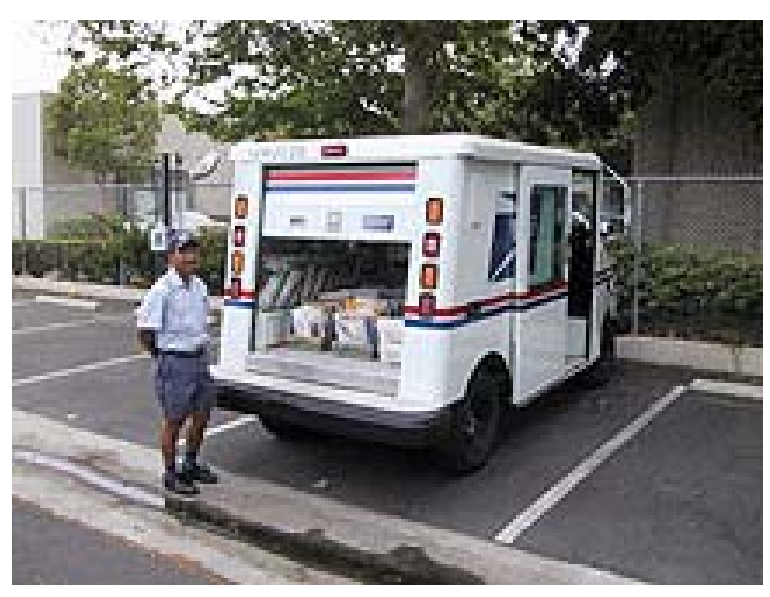

Jim Francfort January 2002 


\section{Disclaimer}

This document highlights work sponsored by agencies of the U.S. Government. Neither the U.S. Government nor any agency thereof, nor any of their employees, makes any warranty, express or implied, or assumes any legal liability or responsibility for the accuracy, completeness, or usefulness of any information, apparatus, product, or process disclosed, or represents that its use would not infringe privately owned rights. Reference herein to any specific commercial product, process, or service by trade name, trademark, manufacturer, or otherwise does not necessarily constitute or imply its endorsement, recommendation, or favoring by the U.S. Government or any agency thereof. The views and opinions of authors expressed herein do not necessarily state or reflect those of the U.S. Government or any agency thereof. 
INEEL/EXT-02-00084

\section{Field Operations Program U.S. Postal Service - Fountain Valley Electric Carrier Route Vehicle Testing}

Jim Francfort

January 2002

Idaho National Engineering and Environmental Laboratory Transportation Technology and Infrastructure Department Idaho Falls, Idaho 83415

Prepared for the

U.S. Department of Energy

Assistant Secretary for Energy Efficiency and Renewable Energy Under DOE Idaho Operations Office

Contract No. DE-AC07-99ID13727 


\section{ABSTRACT}

The United States Postal Service (USPS) has ordered 500 light-duty electric carrier route vehicles (ECRV) mostly for their delivery carriers to use in several California locations. The 500 ECRVs have been defined as a demonstration fleet to support a decision on potentially ordering 5,500 additional ECRVs. Several different test methods are being used by the USPS to evaluate the 500 -vehicle deployment. One of these test methods is the ECRV Customer Acceptance Test Program at Fountain Valley, California. Two newly manufactured ECRVs were delivered to the Fountain Valley Post Office and eighteen mail carriers primarily drove the ECRVs on "park and loop" mail delivery routes for a period of 2 days each. This ECRV testing consisted of 36 route tests, 18 tests per vehicle. The 18 mail carriers testing the ECRVs were surveyed for their opinions on the performance of the ECRVs. The U.S. Department of Energy, through its Field Operations Program, is supporting the USPS's ECRV testing activities both financially and with technical expertise. As part of this support, Field Operations Program personnel at the Idaho National Engineering and Environmental Laboratory have compiled this report, based on data generated by the USPS and its testing contractor (Ryerson, Master and Associates, Inc.).

During the 36 route tests, the two test vehicles were driven a total of 474 miles, averaging 13 miles per test. The distance of the 36 route tests ranged from 4 to 34 miles. Both miles driven and State-ofCharge (SOC) data was collected for only 28 of the route tests. During these 28 tests, the ECRVs were driven a total of 447 miles. The SOC used during the 28 tests averaged a $41 \%$ decrease and the average distance driven was 16 miles. This suggests that a 16-mile route uses almost half of the ECRV's battery

energy. The 18 carriers also rated 12 ECRV traits that included the physical design of the ECRVs as well as their performance. Based on a scale of 1 being lowest and 5 being highest, or best, the overall average score for the ECRV was 4.3. The report also includes individual comments from the ECRV drivers. 


\section{CONTENTS}

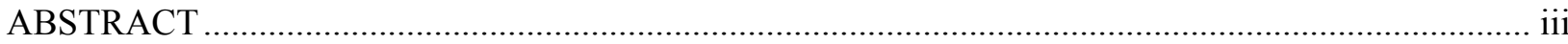

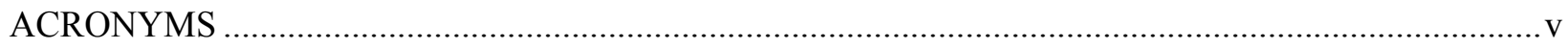

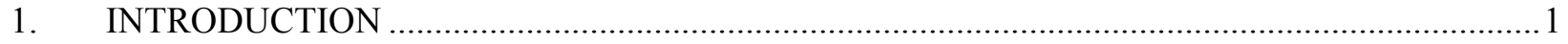

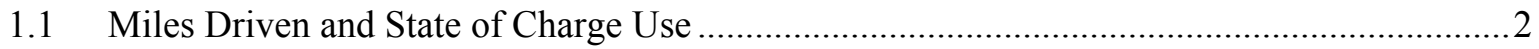

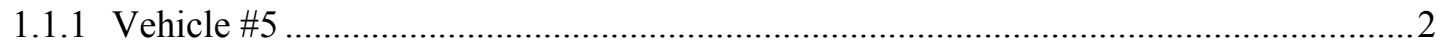

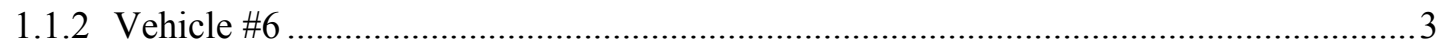

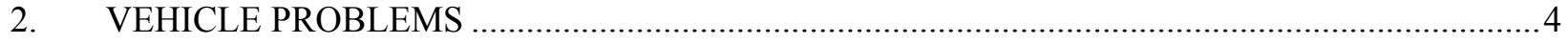

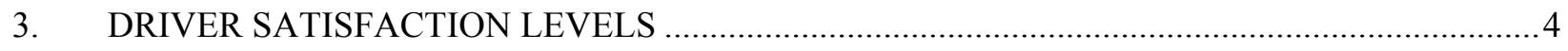

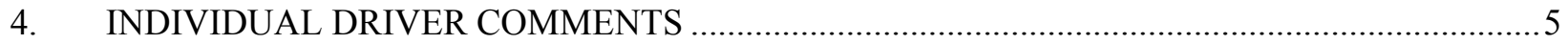

TABLES

Table 1. SOC and miles driven test results for ECRV number 5 .......................................................2

Table 2. SOC and miles driven test results for ECRV number 6 ..............................................................

Table 3. Test driver responses to the twelve questions asked of the 18 ECRV drivers. Each driver drove two vehicles. Some drivers did not respond to questions J, K and L............................................4

Table 4. Vehicle comments received from 17 of 18 ECRV test drivers. ...................................................5 


\section{ACRONYMS}

DOE U.S. Department of Energy

ECRV Electric Carrier Route Vehicle

EV Electric Vehicle

RMA Ryerson, Master and Associates, Inc.

SOC state-of-charge

USPS United States Postal Service 


\section{INTRODUCTION}

The United States Postal Service (USPS) has ordered 500 light-duty electric carrier route vehicles (ECRV) mostly for their delivery carriers to use in several California locations. The 500 ECRVs have been defined as a demonstration fleet to support a decision on potentially ordering 5,500 additional ECRVs. Several different test methods are being used by the USPS to evaluate the 500-vehicle deployment. One of these test methods is the ECRV Customer Acceptance Test Program at Fountain Valley, California. The U.S. Department of Energy, through its Field Operations Program, is supporting the USPS's ECRV testing activities both financially and with technical expertise. As part of this support, Field Operations Program personnel at the Idaho National Engineering and Environmental Laboratory have compiled this report, based on data generated by the USPS and its testing contractor (Ryerson, Master and Associates, Inc.).

The Customer Acceptance Test was conducted from July 11 through August 16, 2000. Two newly manufactured ECRVs (vehicle numbers \#5 and \#6) were delivered to the Fountain Valley Post Office following installation of charging systems at the site. Eighteen mail carriers drove the ECRVs on their normal mail delivery routes for a period of two days each. Prior to driving the vehicles, the mail carriers received training on the operation of the ECRVs and participated in a short practice drive with an experienced electric vehicle operator.

The ECRV testing consisted of 36 route tests, 18 tests per vehicle. The 18 USPS employees drove the vehicles while delivering mail in their normal routes. Sixteen of the drivers drove each vehicle once, while the other two drivers each drove the same vehicle twice. Two of the drivers operated "Express" routes. Of the remaining 16 drivers, 14 operate Park \& Loop routes and 2 operate Mounted routes. Express routes refers to expedited delivery and collection activities - the employee delivers Express Mail, packages and/or makes on-demand or scheduled pick-ups of mail, throughout a postal delivery area. The Park \& Loop routes include a combination of driving to various locations on a route and walking portions of the route. The Mounted routes encompass deliveries to mail boxes from the vehicle.

At the end of each day of driving the ECRVs, the mail carriers filled out a survey form. Within a few days of completing their two day test drive, the mail carriers were interviewed over the phone to clarify data entered on the survey forms, and to obtain any additional comments on vehicle performance.

Ryerson, Master and Associates, Inc. (RMA), under contract to the USPS, performed the following tasks on the Customer Acceptance Test:

- $\quad$ Participated in the Customer Acceptance Test start-up and training meeting at the Fountain Valley Post Office

- $\quad$ Communicated with Fountain Valley Post Office personnel throughout the test to facilitate mail carrier driving schedules and the collection of data

- $\quad$ Reviewed each survey form the day after the form was completed by the mail carrier

- $\quad$ Conducted phone interviews with each mail carrier after they completed their 2-day test drive

- Facilitated response by Ford personnel when vehicle service calls were needed 
- $\quad$ Documented the phone interviews on standardized interview forms

- $\quad$ Prepared a spreadsheet showing the test results, and prepared a summary of the mail carrier comments provided on the survey forms and during the interviews.

\subsection{Miles Driven and State of Charge Use}

All the routes driven by the 18 USPS personnel are described as flat, and the weather was described as clear for all of the tests. The odometer reading on the ECRVs at the beginning of the testing was 208 miles for vehicle \#5 and 293 miles for vehicle \#6. (Please note that throughout the report the \% state-of-charge (SOC) decrease refers to the decrease from X\% SOC to X\% SOC. For instance, a decrease in SOC from $75 \%$ to $25 \%$ is defined as a decrease of $50 \%$.)

\subsubsection{Vehicle \#5}

Table 1 reports the SOC meter change and miles driven data for 14 of the 18 tests performed on Vehicle \#5. The SOC percent decrease averaged $39 \%$ and an average of 13 miles was driven per test. For vehicle \#5, the largest reported SOC decrease during two drive tests was $75 \%$ when 28 and 14 miles were driven respectively. The most miles driven were 28 miles when the SOC decrease was $75 \%$. The least miles driven during one test was 9 miles and the SOC decrease was 25\%. During eight tests, $25 \%$ SOC was used and the miles driven for the eight tests averaged 9 miles, ranging from 4 to 12 miles.

Table 1. SOC and miles driven test results for ECRV number 5.

\begin{tabular}{|l|l|l|l|l|l|l|}
\hline Test \# & $\begin{array}{l}\text { Test } \\
\text { Date }\end{array}$ & $\begin{array}{l}\text { Average Air } \\
\text { Temp }^{\circ} \mathrm{F}\end{array}$ & SOC Begin \% & SOC End \% & $\begin{array}{l}\text { Route Length } \\
\text { (miles) }\end{array}$ & $\begin{array}{l}\text { Miles } \\
\text { Driven }\end{array}$ \\
\hline 1 & $7 / 12$ & 70 & 100 & 25 & Varies & 28 \\
\hline 2 & $7 / 14$ & 73 & 100 & 75 & 5 & 4 \\
\hline 3 & $7 / 15$ & 75 & No data & No data & 5 & 10 \\
\hline 4 & $7 / 17$ & 78 & 100 & 63 & 13 & 13 \\
\hline 5 & $7 / 18$ & 80 & 100 & 75 & 10 & 10 \\
\hline 6 & $7 / 19$ & No data & 100 & 75 & 12 & 10 \\
\hline 7 & $7 / 20$ & 93 & 100 & 75 & 20 & 8 \\
\hline 8 & $7 / 21$ & 81 & No data & No data & 10 & 11 \\
\hline 9 & $7 / 22$ & 83 & 75 & 25 & 17 & 17 \\
\hline 10 & $7 / 24$ & No data & 75 & 50 & 10 & 10 \\
\hline 11 & $7 / 25$ & 84 & 100 & 75 & 10 & 12 \\
\hline 12 & $7 / 26$ & 82 & 100 & 50 & 18 & 18 \\
\hline 13 & $7 / 27$ & 85 & No data & No data & 14 & 14 \\
\hline 14 & $7 / 28$ & No data & 100 & 75 & 12 & 12 \\
\hline 15 & $7 / 29$ & 80 & 100 & 75 & 9 & 9 \\
\hline 16 & $7 / 31$ & 74 & 100 & 25 & 17 & 14 \\
\hline 17 & $8 / 01$ & 81 & 100 & 50 & 14 & 14 \\
\hline 18 & $8 / 02$ & 80 & No data & No data & 10 & 10 \\
\hline
\end{tabular}




\subsubsection{Vehicle \#6}

Table 2 reports the SOC change and miles driven data for 14 of 18 tests for Vehicle \#6. The SOC decrease averaged $44 \%$ and an average of 19 miles was driven per test. For vehicle \#6, the largest reported SOC decrease was 100\% when 34 miles were driven. The least miles driven during a single test was twice reported as 9 miles when 25 and 50\% SOC was used. During 5 tests, $25 \% \mathrm{SOC}$ was used and the miles driven for the 5 tests averaged 13 miles, ranging from 9 to 17 miles.

Vehicles \#5 and \#6 were driven a total of 474 miles, averaging 13 miles per test, ranging from 4 to 34 miles per test. For those 28 tests when both miles driven and SOC decreases were reported, both vehicles were driven a total of 447 miles. The SOC used during the 28 tests averaged a $41 \%$ SOC decrease and the average distance was 16 miles.

Table 2. SOC and miles driven test results for ECRV number 6.

\begin{tabular}{|l|l|l|l|l|l|l|}
\hline Test \# & $\begin{array}{l}\text { Test } \\
\text { Date }\end{array}$ & $\begin{array}{l}\text { Average Air } \\
\text { Temp }{ }^{\circ} \mathrm{F}\end{array}$ & SOC Begin \% & SOC End \% & $\begin{array}{l}\text { Route Length } \\
\text { (miles) }\end{array}$ & $\begin{array}{l}\text { Miles } \\
\text { Driven }\end{array}$ \\
\hline 1 & $7 / 12$ & 80 & 50 & 40 & 10 & 10 \\
\hline 2 & $7 / 15$ & 75 & 75 & 25 & 17 & 17 \\
\hline 3 & $7 / 17$ & 80 & No data & No data & 10 & 10 \\
\hline 4 & $7 / 18$ & 78 & 100 & 63 & 13 & 13 \\
\hline 5 & $7 / 19$ & 93 & No data & No data & 20 & 12 \\
\hline 6 & $7 / 20$ & No data & 100 & 75 & 12 & 9 \\
\hline 7 & $7 / 21$ & 78 & 100 & 50 & 10 & 9 \\
\hline 8 & $7 / 22$ & 83 & No data & No data & 10 & 10 \\
\hline 9 & $7 / 24$ & 85 & 50 & 25 & 10 & 16 \\
\hline 10 & $7 / 25$ & 78 & 100 & 75 & 10 & 10 \\
\hline 11 & $7 / 26$ & 85 & No data & No data & 14 & 13 \\
\hline 12 & $7 / 27$ & No data & 100 & 25 & 18 & 19 \\
\hline 13 & $7 / 28$ & 80 & 100 & 75 & 9 & 17 \\
\hline 14 & $7 / 29$ & No data & 100 & 50 & 12 & 14 \\
\hline 15 & $7 / 31$ & 81 & 100 & 50 & 14 & 15 \\
\hline 16 & $8 / 01$ & 77 & 100 & 25 & 17 & 14 \\
\hline 17 & $8 / 02$ & No data & 100 & 75 & 10 & 13 \\
\hline 18 & $8 / 16$ & 78 & 100 & 0 & Varies & 34 \\
\hline
\end{tabular}




\section{VEHICLE PROBLEMS}

A number of service calls by the vehicle and charger manufacturers were necessary during the Customer Acceptance Test. One vehicle had to be retrieved during use, and then repaired, when the vehicle repeatedly went into reverse when the gear selector was placed in the drive position. One vehicle had to be retrieved during use when the key could not be turned in the ignition switch after the wheels had been curbed. The rear cargo door locks and front door locks on both vehicles had to be repaired. Lastly, the charger system timer settings needed adjustment to enable proper nighttime charging of the vehicles.

\section{DRIVER SATISFACTION LEVELS}

The 18 USPS drivers were each asked 12 questions (see Table 3) about each of the two vehicles that they test-drove. The drivers were asked to rate the overall performance and characteristics the ECRVs from 1 to 5, with 1 defined as the lowest or "poor" score and 5 as the highest or "best" score. Overall, the vehicle was rated fairly well except for how easy it was to get in and out of (question $\mathrm{H}$ - Table 3) and the comfort of the seat (question I - Table 3). However, the various body sizes of the drivers probably account somewhat for these lower scores (2.9 and 3.7). The average weight of the drivers was 167 pounds, ranging from 140 to 230 pounds. The average height of the drivers was $5 \mathrm{ft} 9 \mathrm{in}$., ranging from $5 \mathrm{ft} 4$ in. to $6 \mathrm{ft} 4 \mathrm{in}$. Overall, the charger was rated highest and the ECRV performance was also rated fairly high (Questions A, B, C, D, and F).

Table 3. Test driver responses to the twelve questions asked of the 18 ECRV drivers. Each driver drove two vehicles. Some drivers did not respond to questions J, K and L.

\begin{tabular}{|l|c|c|}
\hline \multicolumn{1}{|c|}{ Evaluation Variables } & Average Rating & Number of Responses \\
\hline A. Overall handling & 4.4 & 36 \\
\hline B. Cornering stability & 4.3 & 36 \\
\hline C. Braking ability & 4.5 & 36 \\
\hline D. Steering response & 4.4 & 36 \\
\hline E. Ease of use of controls & 4.6 & 36 \\
\hline F. Acceleration & 4.5 & 36 \\
\hline G. All-around visibility & 4.0 & 36 \\
\hline H. Ease of getting in and out & 2.9 & 36 \\
\hline I. Seat comfort & 3.7 & 22 \\
\hline J. Heater and defroster & 4.5 & 35 \\
\hline K. State-of-charge meter & 4.6 & 35 \\
\hline L. Charger station & 4.8 & 416 \\
\hline Overall Weighted Average & 4.3 & 36 \\
\hline
\end{tabular}




\section{INDIVIDUAL DRIVER COMMENTS}

The individual comments received from the drivers are provided below (Table 4). The comments generally reflect the scores from Table 3, with the ease of entering and exiting the vehicle (question $\mathrm{H}$, in Table 3 ) receiving many comments.

Table 4. Vehicle comments received from 17 of 18 ECRV test drivers.

Step down from cab too large; oversized back bumper makes it difficult to reach mail trays in back; back door latch malfunctioned.

Step down from cab too large; oversized back bumper makes it difficult to reach mail trays in back; parking brake difficult to pull up; back door pull down loop too high to reach from ground level.

Parking brake difficult to pull up; back door pull down loop too high to reach from ground level; sun glare off back bumper surface is too bright; interior auxiliary fan should turn off automatically when vehicle turned off; round mirrors did not extend out far enough for good front and back visibility.

Step down from cab too large; uncomfortable seat; vehicle charge gauge was confusing to read.

Step down from cab too large; oversized back bumper makes it difficult to reach mail trays in back; high vehicle height makes it difficult to reach low mailboxes on mounted route.

Oversized back bumper makes it difficult to reach mail trays in back; parking brake difficult to pull up; back door pull down loop too high to reach from ground level.

Back door pull down loop too high to reach from ground level; sun glare off back bumper surface is too bright; interior auxiliary fan should turn off automatically when vehicle turned off; need grab handles on back to board vehicle rear compartment; steering wheel blocks driver's view of dashboard instrument panel; seat adjustment has sharp edges.

Step down from cab too large; oversized back bumper makes it difficult to reach mail trays in back; back door pull down loop too high to reach from ground level; steering takes effort.

Oversized back bumper makes it difficult to reach mail trays in back; back door pull-down loop too high to reach from ground level; sun glare off back bumper surface is too bright; back up beeper should be installed and automatically actuated when backing up and should be located on vehicle to be heard by people in rear of vehicle; poor turning radius (can't make U-turn easily).

Oversized back bumper makes it difficult to reach mail trays in back; sun glare off back bumper surface is too bright; back up beeper should be installed and automatically actuated when backing up; parking brake difficult to pull up; stationary seat belt latch is difficult to reach when buckling up; interior auxiliary fan should turn off automatically when vehicle turned off.

Step down from cab too large; oversized back bumper makes it difficult to reach mail trays in 
back. Back door pull down loop too high to reach from ground level; sun glare off back bumper surface is too bright; back up beeper should be installed and automatically actuated when backing up; parking brake difficult to pull up; window in cargo area may be security problem.

Step down from cab too large; oversized back bumper makes it difficult to reach mail trays in back; back door pull down loop too high to reach from ground level; parking brake difficult to pull up; interior auxiliary fan should turn off automatically when vehicle turned off; poor turning radius (can't make U-turn easily); separate key for door lock and for ignition, should be one key.

Operating brakes and steering takes effort; left side mirrors too low for good side visibility.

Oversized back bumper makes it difficult to reach mail trays in back; stationary seat belt latch is difficult to reach when buckling up.

Step down from cab too large; oversized back bumper makes it difficult to reach mail trays in back; back door pull down loop too high to reach from ground level; parking brake difficult to pull up; sun glare off back bumper surface is too bright.

Step down from cab too large; oversized back bumper makes it difficult to reach mail trays in back; back door pull down loop too high to reach from ground level; back door pull down loop too high to reach from ground level; interior auxiliary fan should turn off automatically when vehicle turned off; stationary seat belt latch is difficult to reach when buckling up; window in cargo area may be security problem; vehicle is so silent when operating, bystanders may not be aware vehicle is moving.

Major problem with ignition key not extracting when wheels locked in curbed position, step down from cab too large; oversized back bumper makes it difficult to reach mail trays in back; parking brake difficult to pull up; sun glare off back bumper surface is too bright; interior auxiliary fan should turn off automatically when vehicle turned off; concerned about getting electrocuted when using charger under wet conditions; could not remove key from lock on rear door. 